\title{
Adherence to Highly Active Antiretroviral Therapy and Its Association with HIV Disclosure status among People Living with HIV/AIDS in Ethiopia: A systematic review and Meta-Analysis.
}

Abere Woretaw Azagew ( $\nabla$ wabere@ymail.com )

University of Gondar https://orcid.org/0000-0002-6270-5992

Chilot Kassa Mekonnen

University of Gondar

Abebaw Jember Ferede

University of Gondar

Kassahun Gebeyehu Yazew

University of Gondar

Zewdu Baye Tezera

University of Gondar

Research article

Keywords: HAART, ART, Adherence, HIV disclosure, Adult HIV positive

Posted Date: May 11th, 2020

DOI: https://doi.org/10.21203/rs.3.rs-18608/v1

License: (c) (i) This work is licensed under a Creative Commons Attribution 4.0 International License.

Read Full License 


\section{Abstract}

Background:

Adherence to Highly Active Antiretroviral Therapy (HAART) medication is the pressing public health problem worldwide. Non-adherence to HAART leads to treatment failure, immunologic failure, and virological failure. Despite different interventions made; still, HAART medication adherence among adult people living with HIV/AIDS (PLWHA) is inconsistent across studies and the effect of HIV disclosure status was not well studied. Therefore this study determines the pooled prevalence of HAART adherence and its relationship with HIV disclosure status among Adult PLWHA.

Methods

We searched 3247 both published and unpublished original articles from January 2016 to November 2019 in Ethiopia using different search engines. Data were extracted using Microsoft excel. New Castle Ottawa Scale quality assessment tool was used. STATA software version 11 was used for analysis. A random-effects meta-analysis was performed. Cochran $\mathrm{Q}$ statistics and $\mathrm{I}^{2}$ were used to estimate heterogeneity. Eggers and Begg's test was used to assess the publication bias.

Results

A total of 15 studies for systematic review and four studies for Meta-analysis were used. The pooled prevalence of HAART medication adherence is found to be $81.19 \%(80.132,82.248)$. In the subgroup analysis, the pooled prevalence of HAART adherence was $79.82 \%(73.19,86.45)$ in the Oromia region, $82.51 \%(73.14,91.87)$ in the Amhara region, and $72.7 \%(63.78,81.61)$ in the SNNPR. HIV disclosure improves HAART adherence by nearly three times compared to non-HIV disclosed HAART users $(\mathrm{AOR}=2.99,95 \% \mathrm{Cl}: 1.88,4.77)$.

Conclusions

The pooled prevalence of HAART adherence among adult PLWHA was found to be low. Having HIV disclosure improved HAART medication adherence.

\section{Background}

The human immune deficiency virus(HIV) affects many segments of the world population in different aspects(1). Africa, Asia, and Latin America were the major continents affected by HIV(2). In this regard in 2016, there were about 36.7 million people lived with HIV(3).

Globally and in sub-Saharan Africa there were 160,000 and 110,000 children had got HIV infection in different ways respectively (2-4). According to the WHO report in 2016, an estimated 2.1 million 
adolescents were living with HIV of this $84 \%$ were living in sub-Saharan Africa(5). Sub-Saharan Africa(SSA) is the home for $76 \%$ of the global morbidity and $75 \%$ mortality of HIV/AIDS(6). According to the WHO global burden disease report at the end of 2016 in Ethiopia, there had been 39,140 new HIV infections,768,040 people living with the virus, and 28,650 HIV/AIDS deaths(6). Having good adherence to antiretroviral therapy (ART) known to prolong the life of HIV patients(7). On the contrary; nonadherence to antiretroviral therapy(ART) could lead to different complications such as treatment, immunological, and virological failure $(8,9)$. The human immune deficiency virus infection does not only affect the patient but also the families, communities, and the development of the country at large $(2,6)$. Furthermore, the country could also suffer from other infectious diseases, and end up with economic instability(10).

Antiretroviral therapy has a crucial clinical effect in decreasing viral replication and viral load which in turn increases the CD4 level and decreases the progress of HIV/AIDS(11). Though, the clinical outcome of ART depends mainly on the adherence of the patients to antiretroviral therapy (ART). Studies showed that ART adherence is second to CD 4 count for accurately predicting the prognosis of AIDS and death $(9,12)$. There are different factors which have been contributing for ART adherence as stated by studies such as level of awareness about HIV, counseling about adherence, absence of co-morbidity, social support, a substance used, a side effect of the drug, depression, and disclosure(13-16).

As far as known, there is no published systematic review and meta-analysis on this topic. Besides, the lack of high quality data on the level of adherence and its associated factors was a great challenge to the national HIV/AIDS control programs for providing accurate data to run intervention strategies. This study aimed to determine the pooled adherence of ART and its factors among adults PLHIV in Ethiopia.

\section{Methods}

\section{Study design and searching strategy}

This systematic review study was carried out from published and unpublished literature to determine the pooled prevalence of adherence to antiretroviral therapy among adult people living with HIV/AIDS patients in Ethiopia. Studies were found through electronic and manual searches using databases; PSYCH INFO, EMBASE, MIDLINE/Pub med, Google scholar and Google for gray literatures. Using search terms; ((adherence or "non-adherence" or compliance or "non-compliance" or "missing dose" and "Highly Active Anti Retroviral Therapy" or HAART or "Anti Retroviral Therapy" or ART) and ("Adult People Living with HIV/AIDS" or "Adult PLWHA" or Adult HIV positive patients) and Ethiopia)) restricted to the publication date from January 2016 to November 2019.

\section{Inclusion Criteria}

All observational studies reported on the adherence or non-adherence or non-compliance or a missed dose of Highly Active Anti Retroviral Therapy among Adult people Living with HIV/AIDS were included in 
the study. Peer-reviewed studies with cross-sectional design and primary outcome of interest were included in the study.

\section{Exclusion criteria}

Those studies which showed an unclear prevalence of adherence to HAART and their HIV disclosure status among adult PLWHIV were excluded in the study.

\section{Data extraction}

Two reviewers (AW \& ZB) screened the titles and abstracts of identified studies and assessed the full text of potentially eligible studies. Any controversy was resolved by consensus. We made some efforts to communicate the authors whenever further information was needed. Data from included studies were extracted independently by these reviewers. Data on the author(s), study year, a region of study, study design, the prevalence of adherence, sample size, and HIV disclosure status were extracted using Microsoft excel. The prevalence of adherence to HAART among adult PLWHA was extracted from each included study CKM, KGY, and AJF critically reviewed the whole manuscript.

\section{Quality Appraisal}

Articles were assessed for quality score using the New Castle Ottawa Scale adapted for cross-sectional studies quality assessment tool, a score of $\geq 5$ out of 10 considered as high quality score. Two authors (AW \& ZB) assessed the quality of each paper. The reviewers compared the quality of appraisal scores and resolved any inconveniency before calculating the final appraisal score. All included studies had a high quality of the score.

\section{Data analysis}

A systematic review of pooled prevalence adherence to HAART was carried out using a random effect model, generating a pooled prevalence with $95 \%$ Cls using STATA software version 11 . Cochrane Q statistics and $\mathrm{I}^{2}$ were used to estimate the presence of heterogeneity. Subgroup analyses by region were carried out because of significant heterogeneity between studies. Sensitivity analysis was used to see the discrepancy among studies. Egger's and Begg's test was used to estimate the publication bias. Trim and fill analysis were used to treat the potential publication bias.

\section{Results}

\section{Selection and Identification of studies}

After removing duplicates, a total of 3247 studies were retrieved of which 3082 studies were rejected just by reading the titles. Of the remaining 165 studies, 143 were excluded after reviewing the abstracts. Fulltext copies of 18 studies that met or potentially met the inclusion criteria were assessed. After further screening 15 papers were retained for inclusion for the systematic review. Of 15 studies included in 
systematic review; 11 studeis were excluded and $4(10,17-19)$ articles were used for meta-analysis (Figure 1).

\section{Characteristics of the articles}

Of the 15 full studies, 8 of them were from the Oromia region, 3 in the Amhara region, 2 in the South nations and nationalities of republic (SNNPR), 1 in Harer, and 1 in Addis Ababa. Relevant features of each study including author, year, a region of study, study design, study population sample size, and prevalence of ART adherence were summarized below ( Table 1).

Table 1: General characteristics of included studies that report the prevalence of HAART adherence and/its association with HIV disclosure status

\begin{tabular}{|c|c|c|c|c|c|}
\hline rr/ Year & Region & Study design & Study population & Sample size(n) & $\begin{array}{l}\text { Prevalence } \\
\text { (\%) }\end{array}$ \\
\hline la et al./2016(20) & Oromia & Cross sectional & Adult people living with HIV & 306 & 65 \\
\hline ?n et al./2019(21) & Oromia & Cross sectional & Adult people living with HIV & 352 & 73.6 \\
\hline et al./2018(10) & Amhara & Cross sectional & Adult people living with HIV & 440 & 88.2 \\
\hline sa et al./2017(22) & Harer & Cross sectional & Adult people living with HIV & 314 & 65 \\
\hline din et al./2017(23) & SNNPR & Cross sectional & Adult people living with HIV & 428 & 77.1 \\
\hline l et al./2016(24) & Oromia & Cross sectional & Adult people living with HIV & 383 & 89.3 \\
\hline et al./2017(25) & Addis Ababa & Cross sectional & Adult people living with HIV & 273 & 80.1 \\
\hline hun et al./2017(26) & Oromia & Cross sectional & Adult people living with HIV & 321 & 72.3 \\
\hline et al./2018(27) & SNNPR & Cross sectional & Adult people living with HIV & 320 & 68 \\
\hline wesen et al./2017(18) & Oromia & Cross sectional & Adult people living with HIV & 190 & 92.6 \\
\hline aye et al./2016(17) & Oromia & Cross sectional & Adult people living with HIV & 420 & 86 \\
\hline ye et al./2019(28) & Amhara & Cross sectional & Adult people living with HIV & 418 & 71.8 \\
\hline tt al./2018(29) & Oromia & Cross sectional & Adult people living with HIV & 160 & 85.6 \\
\hline ga /2019(19) & Oromia & Cross sectional & Adult people living with HIV & 305 & 73.1 \\
\hline stie / 2018(30) & Amhara & Cross sectional & Adult people living with HIV & 352 & 87.2 \\
\hline
\end{tabular}

\section{Adherence to HAART}

Among 15 cross-sectional studies, the prevalence of ART adherence ranges from 65\% (20) to $92.6 \%(18)$. The overall pooled prevalence is found to be $81.19 \%$ (80.132- 82.248) (Table 2). Based on subgroup analysis by region, the pooled prevalence of ART adherence $79.82 \%(73.19,86.45)$ in Oromia region, $82.51 \%(73.14,91.87)$ in Amhara region, and $72.7 \%(63.78,81.61)$ in SNNPR (Figure 2). 
Table 2: The pooled prevalence of HAART adherence among Adult people living with HIV/AIDS in Ethiopia.

\begin{tabular}{|c|c|c|c|c|}
\hline Author/Year & ES & \multicolumn{2}{|c|}{ [95\% Conf. Interval] } & \multirow{2}{*}{$\begin{array}{c}\text { \% Weight } \\
3.92\end{array}$} \\
\hline Dibaba et al. (2016) & 65.000 & 59.656 & 70.344 & \\
\hline Hassen et al. (2019) & 73.600 & 68.995 & 78.205 & 5.28 \\
\hline Molla et al. (2018) & 88.200 & 85.186 & 91.214 & 12.32 \\
\hline Negasa et al. (2017) & 65.000 & 59.724 & 70.276 & 4.02 \\
\hline Nuredin et al. (2017 & 77.100 & 73.119 & 81.081 & 7.07 \\
\hline Efrem et al. (2016) & 89.300 & 86.204 & 92.396 & 11.68 \\
\hline Naod et al. (2017) & 80.100 & 75.364 & 84.836 & 4.99 \\
\hline Kassahun et al. (2017) & 72.300 & 67.404 & 77.196 & 4.67 \\
\hline Hailu et al (2018) & 68.000 & 62.889 & 73.111 & 4.29 \\
\hline Wendwesen et al.(2017 & 7) 92.600 & 88.878 & 96.322 & 8.08 \\
\hline Shewaye et al. (2016) & 86.000 & 82.682 & 89.318 & 10.17 \\
\hline Aychew et al (2019) & 71.800 & 67.486 & 76.114 & 6.02 \\
\hline Jima etal. (2018) & 85.600 & 80.160 & 91.040 & 3.78 \\
\hline Abadiga (2019) & 73.100 & 68.123 & 78.077 & 4.52 \\
\hline Mengstie (2018) & 87.200 & 83.710 & 90.690 & 9.19 \\
\hline I-V pooled ES & 81.190 & 80.132 & 82.248 & 100.00 \\
\hline \multicolumn{5}{|c|}{ Heterogeneity chi-squared $=257.96($ d.f. $=14) \mathrm{p}=0.000$} \\
\hline \multicolumn{5}{|c|}{ I-squared (variation in ES attributable to heterogeneity) $=94.6 \%$} \\
\hline Test of $E S=0: z=150$ & $.39 p=0.0$ & 000 & & \\
\hline
\end{tabular}

\section{Heterogeneity test}

As shown from the table, the heterogeneity test $\left(1^{2}\right)$ is $94.6 \%$. This indicates there is a considerable variation across studies, but the sensitivity analysis indicates there is no study away from a lower and upper confidence intervals. All the studies concentrated around the point of the estimations. The funnel plot test is asymmetrical (Figure 3 ). 


\section{Publication bias}

Publication bias was detected based on the graphic asymmetry of funnel plots, egger's test $(p<0.05)$, and Begg's test. In the Egger test the p-value is 0.001 which shows that there is a publication bias. Therefore, the author used a random effect model to treat bias. Furthermore, the trim and fill analysis was performed.

\section{The effect of disclosure status on ART Adherence}

To determine the effect of HIV disclosure on ART adherence among PLWHIV, a total of four crosssectional studies $(10,17-19)$ were used. The study showed that HIV disclosure improves ART adherence nearly by three times compared to non disclosed HIV positive ART users (AOR=2.99, 95\% Cl: $1.88,4.77$ ) (Figure 4).

\section{Heterogeneity}

The heterogeneity test $\left(\mathrm{I}^{2}\right)$ is $51.8 \%$ which indicates there is a considerable variation across studies. The funnel plot test is symmetrical. The sensitivity test indicates there is no study away from a lower and upper confidence intervals. All the studies concentrated around the point of the estimations

\section{Publication bias}

Publication bias was detected based on the graphic asymmetry of the funnel plot and egger's test $(\mathrm{p}<$ 0.05). The test indicates the graphic funnel plot is symmetrical and the egger's plot test result was 0.063 .

\section{Discussion}

A high level of adherence to prescribed antiretroviral therapy is considered as a key parameter for successful long-term management of HIV infection. Fifteen-cross sectional studies were used for this review study, and the ART adherence ranges from $65-96.2 \%$. In this systematic review, the pooled prevalence of HAART adherence was found to be $81.19 \%(80.132-82.248)$. In the subgroup analysis, the pooled prevalence of HAART adherence was $79.82 \%(73.19,86.45)$ in the Oromia region, $82.51 \%(73.14$, $91.87)$ in the Amhara region, and $72.7 \%(63.78,81.61)$ in Southern nations nationalities and people. Our study finding is higher in a study conducted in $>26$ countries with an adherence rate of $63 \%(31)$, India $70 \%$ (32), $62.3 \%$ in 53 countries (33). The discrepancy is due to variation in using the optimal level of ART adherence, the cut point used, use of multiple interventions, and use of clinical trials. The finding of this review study is lower than a study conducted in Tanzania $84 \%(34,35)$, Botswana, Tanzania and Uganda; on which the ART adherence was $98 \%$ for two-day recall, $92 \%$ for one-month self recall and $93 \%$ for onemonth pharmacy pill count (34), and in a reviewed articles $90 \%$ (36), national ART guidelines in which adherence is $>95 \%(37)$.

The finding of this study revealed that HIV disclosure improved ART adherence nearly by three times compared to non-HIV disclosed ART users (AOR $=2.99,95 \% \mathrm{Cl}: 1.88,4.77)$. HIV disclosure is an adherence 
enhancing intervention (38). The study is supported by a global evidence study using a treatment supporter that enhances ART adherence (39). Using ART adherence supporter is a tool/an intervention for viral load suppression (40). A study was done on developed and developing nations' fear of disclosure and suspicious on treatment decrease ART adherence (41). Sero-status disclosure to others results in a higher rate of ART adherence (42). Early and fully disclosure improved ART adherence. Disclosure is an essential tool in improving adherence and reduce mortality (43). HIV disclosure is a predictor of ART adherence HIV patients who disclosed their sero-status have strong support at the household level, but the stigma is the obstacle for disclosure (44). Stigma, lack of care/social support, and non-disclosure of HIV status are barriers to ART adherence $(34,45)$. HIV disclosing relieves stress and anxiety, providing a trusting relationship between the patient and supporter, and sharing positive messages(37). The authors used ART adherence measured by different adherence measurement scales which may over/underestimate the ART adherence status.

\section{Conclusion}

The pooled prevalence of HAART adherence among adult PLWHA was found to be low. Having HIV disclosure improved HAART medication adherence. HAART adherence and HIV disclosure have a crucial role in the treatment outcome of HIV patients. Successful treatment of HIV/AIDS with HAART improves the patient's CD4 count and decreases viral load.

\section{Abbreviations}

AIDS; Acquired Immune Deficiency Syndrome, AOR; Adjusted Odds Ratio, ART; Antiretroviral Therapy, HAART; Highly Active Antiretroviral Therapy, HIV; Human immune deficiency Virus, PLWHIV; People Living With Human Immune-deficiency Virus

\section{Declarations}

\section{Ethical Approval and consent to participate}

Not applicable because no primary data collected

\section{Consent for publication}

Not applicable

\section{Availability of data and Material}

The datasets used and/or analysed during the current study are available from the corresponding author on reasonable request.

Competing interest 
The author declare that there is no competing of interest

\section{Funding}

The authors' did not receive any funding

\section{Authors' contribution}

AWA conceived the idea and design this research work. CKM, AJF, KGY, and ZBT participated in the data extraction, analysis, and interpretation. All the authors approved the final draft of the manuscript.

\section{Acknowledgments}

Our special gratitude goes to the authors of included studies which help us to do this systematic review and meta-analysis.

\section{References}

1. Cohen MS, Hellmann N, Levy JA, DeCock K, Lange J. The spread, treatment, and prevention of HIV-1: evolution of a global pandemic. J Clin Investig. 2008;118(4):1244-54.

2. Hamilton E, Bossiky B, Ditekemena J, Esiru G, Fwamba F, Goga AE, et al Using the PMTCT cascade to accelerate achievement of the global plan goals. Journal of acquired immune deficiency syndromes (1999). 2017;75(1):S27.

3. Unaids J. Fact sheet-latest global and regional statistics on the status of the AIDS epidemic. Geneva: UNAIDS; 2017.

4. Organization WH. Progress report 2016: prevent HIV, test and treat all: WHO support for country impact. World Health Organization, 2016.

5. Slogrove AL, Sohn AH. The global epidemiology of adolescents living with HIV: time for more granular data to improve adolescent health outcomes. Current Opinion in HIV AIDS. 2018;13(3):1708.

6. Fullman N, Barber RM, Abajobir AA, Abate KH, Abbafati C, Abbas KM, et al. Measuring progress and projecting attainment on the basis of past trends of the health-related Sustainable Development Goals in 188 countries: an analysis from the Global Burden of Disease Study 2016. The Lancet. 2017;390(10100):1423-59.

7. Yared M, Tibebu S, Emmart P. Equity and Access to ART in Ethiopia Washington: Initiative HP 2010 Futures Group. Task Order. 2010;1.

8. Gesesew HA, Ward P, Hajito KW, Feyissa GT, Mohammadi L, Mwanri L. Discontinuation from antiretroviral therapy: a continuing challenge among adults in HIV care in Ethiopia: a systematic review and meta-analysis. PloS one. 2017;12(1):e0169651.

9. Oguntibeju 00. Quality of life of people living with HIV and AIDS and antiretroviral therapy. HIV/AIDS (Auckland, NZ). 2012;4:117. 
10. Molla AA, Gelagay AA, Mekonnen HS, Teshome DF. Adherence to antiretroviral therapy and associated factors among HIV positive adults attending care and treatment in University of Gondar Referral Hospital, Northwest Ethiopia. BMC Infect Dis. 2018;18(1):266.

11. Mayer KH, Shisana O, Beyrer C. AIDS 2016: from aspiration to implementation. The Lancet. 2016;387(10037):2484-5.

12. Nachega JB, Hislop M, Nguyen H, Dowdy DW, Chaisson RE, Regensberg L, et al Antiretroviral therapy adherence, virologic and immunologic outcomes in adolescents compared with adults in southern Africa. Journal of acquired immune deficiency syndromes (1999). 2009;51(1):65.

13. Biressaw S, Abegaz WE, Abebe M, Taye WA, Belay M. Adherence to Antiretroviral Therapy and associated factors among HIV infected children in Ethiopia: unannounced home-based pill count versus caregivers' report. BMC Pediatr. 2013;13(1):132.

14. Letta S, Demissie A, Oljira L, Dessie Y. Factors associated with adherence to Antiretroviral Therapy (ART) among adult people living with HIV and attending their clinical care, Eastern Ethiopia. BMC international health human rights. 2015;15(1):33.

15. Silva JAG, Dourado I, Brito, AMd, Silva CALd. Factors associated with non-adherence to antiretroviral therapy in adults with AIDS in the first six months of treatment in Salvador, Bahia State, Brazil. Cadernos de saude publica. 2015;31(6):1188-98.

16. Gebrezgabher BB, Kebede Y, Kindie M, Tetemke D, Abay M, Gelaw YA. Determinants to antiretroviral treatment non-adherence among adult HIV/AIDS patients in northern Ethiopia. AIDS research therapy. 2017;14(1):16.

17. Fituma S. HIV Positive Status Disclosure and Highly Active Antiretroviral therapy Adherence among People living with HIV in Ambo Hospital, West Shewa Zone. Oromia Region: Addis Abeba Universty; 2016.

18. Abayneh W, Obse N, Naba T. Factors Associated With Level of Adherence to Antiretroviral Therapy in People Living with HIV/AIDS at Adama Hospital Medical College Art Clinic, Oromiya Regional State, Ethiopia. International Journal of HIV/AIDS Prevention, Education and Behavioural Science. 2017;3(3):22 - 7.

19. POSITIVE ADULTS ATTENDING TREATMENT AT NEKEMTE REFERRAL HOSPITAL WEST ETHIOPIA infectious diseases 2019.

Abadiga M. ADHERENCE TO ANTIRETROVIRAL THERAPY AND ASSOCIATED FACTORS AMONG HIV. POSITIVE ADULTS ATTENDING TREATMENT AT NEKEMTE REFERRAL HOSPITAL, WEST ETHIOPIA. infectious diseases 2019.

20. Dibaba B, Hussein M. Factors associated with non-adherence to antiretroviral therapy among adults living with HIV/AIDS in Arsi zone, Oromia. Journal of AIDS and Clinical Research. 2017;8(1).

21. Hassen A, Mohammed Y. Antiretroviral Therapy Adherence Level and Associated Factors Among HIV/AIDS Patients in Jimma Zone Government Health Facilities, ART Clinics, South-west Ethiopia. International Journal of Multicultural Multireligious Understanding. 2019;5(5):331-41. 
22. Negesa L, Demeke E, Mekonnin W. Adherence to Antiretroviral Therapy and Factors affecting among People Living with HIV/AIDS and Taking Antiretroviral Therapy, Dire Dawa Town, Eastern Ethiopia. J Infect Dis Treat. 2017;3(1):5.

23. Azmach NN. Adherence to Antiretroviral Therapy and Associated Factors Among Adult ARV Users in Arba Minch Hospital, Southern Ethiopia.

24. Negash E, Wakgari N, Wasie B, Edris M, Bekele G. Adherence to antiretroviral therapy and its associated factors among HIV positive patients in Nekemte public health institutions, West Ethiopia. HIV \& AIDS Review. 2016;15(3):116 - 21.

25. Firdu N, Enquselassie F, Jerene D. HIV-infected adolescents have low adherence to antiretroviral therapy: a cross-sectional study in Addis Ababa, Ethiopia. Pan African Medical Journal. 2017;27(1).

26. Bidu KT, Babure ZK. Barriers of adherence to antiretroviral therapy among HIV/AIDS infected persons in Nekemte referral Hospital, East Wollega, Oromia Regional State, Western Ethiopia, 2017. Journal of AIDS HIV Research. 2018;10(5):64-76.

27. Koyra H. Adherence to Antiretroviral Therapy among Adult Persons Living with HIV/AIDS in Southern Ethiopia. Int J Virol AIDS. 2018;5:038.

28. Legesse TA, Reta MA. Adherence to Antiretroviral Therapy and Associated Factors among People Living with HIV/AIDS in Hara Town and Its Surroundings, North-Eastern Ethiopia: A Cross-Sectional Study. Ethiop J Health Sci. 2019;29(2):447.

29. Jima F, Tatiparthi R. Prevalence of nonadherence and its associated factors affecting on HIV adults follow-up at antiretroviral therapy clinic in Batu Hospital, Eastern Ethiopia. Indian journal of sexually transmitted diseases AIDS. 2018;39(2):91.

30. Mengistie A, Birhane A, Tesfahun E. Assessment of Adherence to Antiretroviral Therapy Among Adult People Living with HIV/AIDS in North East, Ethiopia. BioRxiv. 2018:492330.

31. Bezabhe WM, Chalmers L, Bereznicki LR, Peterson GM. Adherence to antiretroviral therapy and virologic failure: a meta-analysis. Medicine. 2016;95(15).

32. Mhaskar R, Alandikar V, Emmanuel P, Djulbegovic B, Patel S, Patel A, et al. Adherence to antiretroviral therapy in India: a systematic review and meta-analysis. Indian journal of community medicine: official publication of Indian Association of Preventive Social Medicine. 2013;38(2):74.

33. Kim S-H, Gerver SM, Fidler S, Ward H. Adherence to antiretroviral therapy in adolescents living with HIV: systematic review and meta-analysis. AIDS. 2014;28(13):1945.

34. Hardon A, Davey S, Gerrits T, Hodgkin C, Irunde H, Kgatlwane J, et al. From access to adherence: The challenges of antiretroviral treatment: Studies from Botswana, Tanzania and Uganda 2006. 2006.

35. Ramadhani HO, Thielman NM, Landman KZ, Ndosi EM, Gao F, Kirchherr JL, et al. Predictors of incomplete adherence, virologic failure, and antiviral drug resistance among HIV-infected adults receiving antiretroviral therapy in Tanzania. Clin Infect Dis. 2007;45(11):1492-8.

36. Ortego C, Huedo-Medina TB, Llorca J, Sevilla L, Santos P, Rodríguez E, et al. Adherence to highly active antiretroviral therapy (HAART): a meta-analysis. AIDS Behav. 2011;15(7):1381-96. 
37. Frehiwot N, Mizan K, Seble M, Fethia K, Tekalign M, Zelalem T. National guidelines for comprehensive HIV prevention, care and treatment. Addis Ababa: Ministry of Health; 2014.

38. Kanters S, Park JJ, Chan K, Socias ME, Ford N, Forrest JI, et al. Interventions to improve adherence to antiretroviral therapy: a systematic review and network meta-analysis. The lancet HIV. 2017;4(1):e31-40.

39. Chaiyachati KH, Ogbuoji O, Price M, Suthar AB, Negussie EK, Bärnighausen T. Interventions to improve adherence to antiretroviral therapy: a rapid systematic review. Aids. 2014;28:187-204.

40. Bonner K, Mezochow A, Roberts T, Ford N, Cohn J. Viral load monitoring as a tool to reinforce adherence: a systematic review. JAIDS Journal of Acquired Immune Deficiency Syndromes. 2013;64(1):74-8.

41. Mills EJ, Nachega JB, Bangsberg DR, Singh S, Rachlis B, Wu P, et al. Adherence to HAART: a systematic review of developed and developing nation patient-reported barriers and facilitators. PLoS Med. 2006;3(11):e438.

42. Stirratt MJ, Remien RH, Smith A, Copeland OQ, Dolezal C, Krieger D, et al. The role of HIV serostatus disclosure in antiretroviral medication adherence. AIDS Behav. 2006;10(5):483-93.

43. Cluver LD, Hodes RJ, Toska E, Kidia KK, Orkin FM, Sherr L, et al. 'HIV is like a tsotsi. ARVs are your guns': associations between HIV-disclosure and adherence to antiretroviral treatment among adolescents in South Africa. LWW; 2015.

44. Skhosana NL, Struthers H, Gray GE, McIntyre JA. HIV disclosure and other factors that impact on adherence to antiretroviral therapy: the case of Soweto, South Africa. African Journal of AIDS Research. 2006;5(1):17-26.

45. Achappa B, Madi D, Bhaskaran U, Ramapuram JT, Rao S, Mahalingam S. Adherence to antiretroviral therapy among people living with HIV. North American journal of medical sciences. 2013;5(3):220.

\section{Figures}




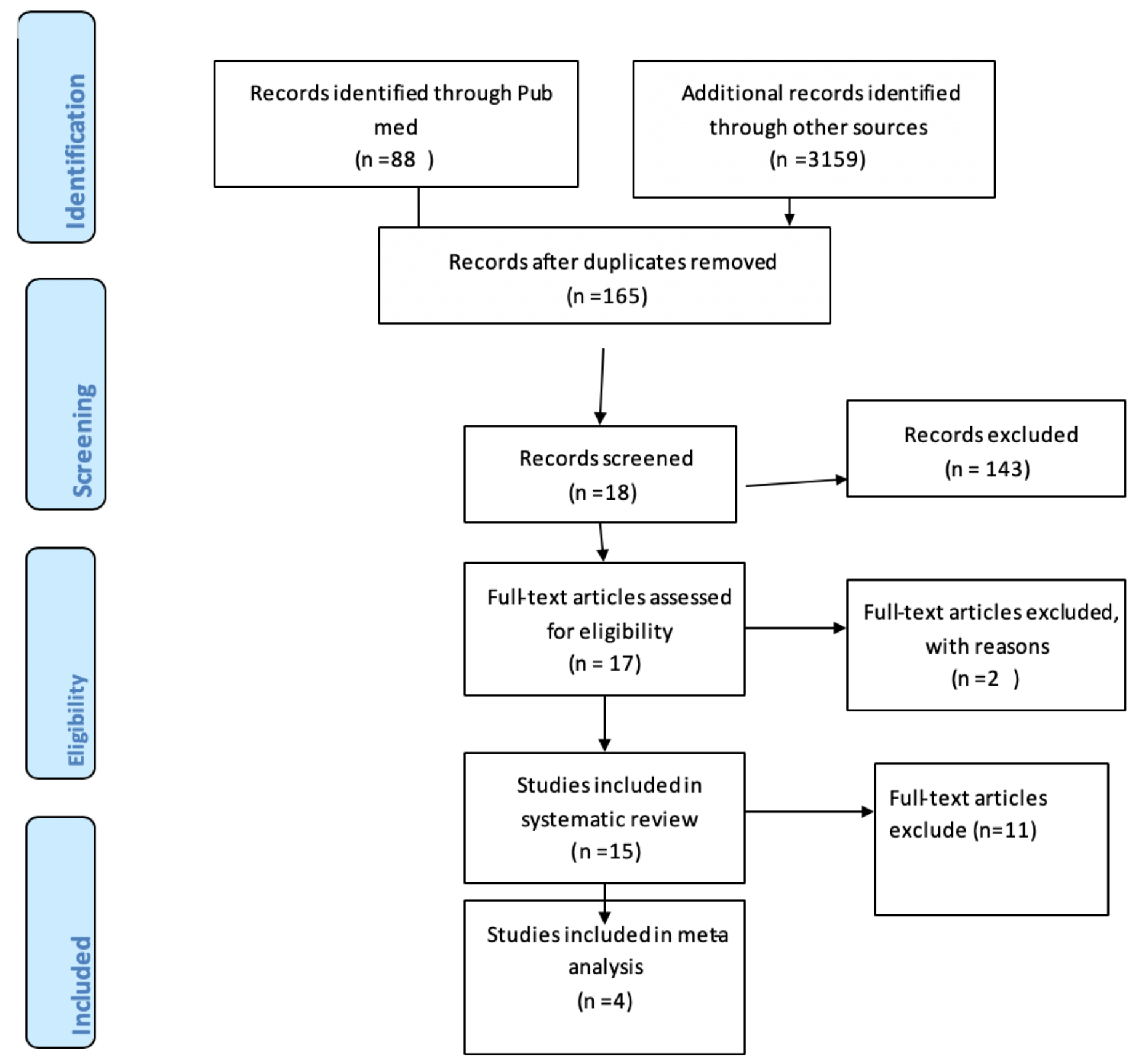

Figure 1

Flow diagram of Study selection 


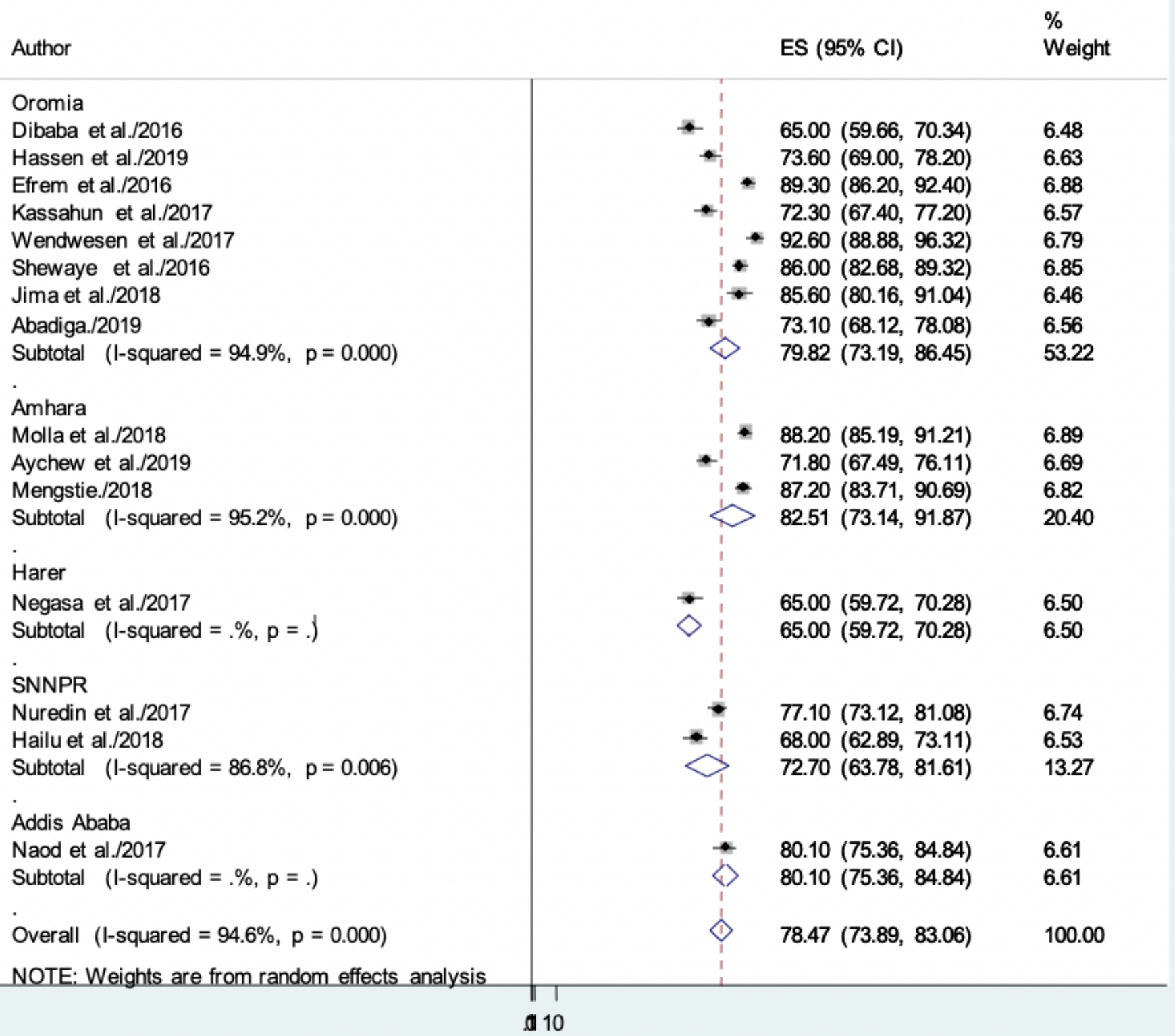

Figure 2

Subgroup analysis shows the pooled prevalence of HAART adherence 


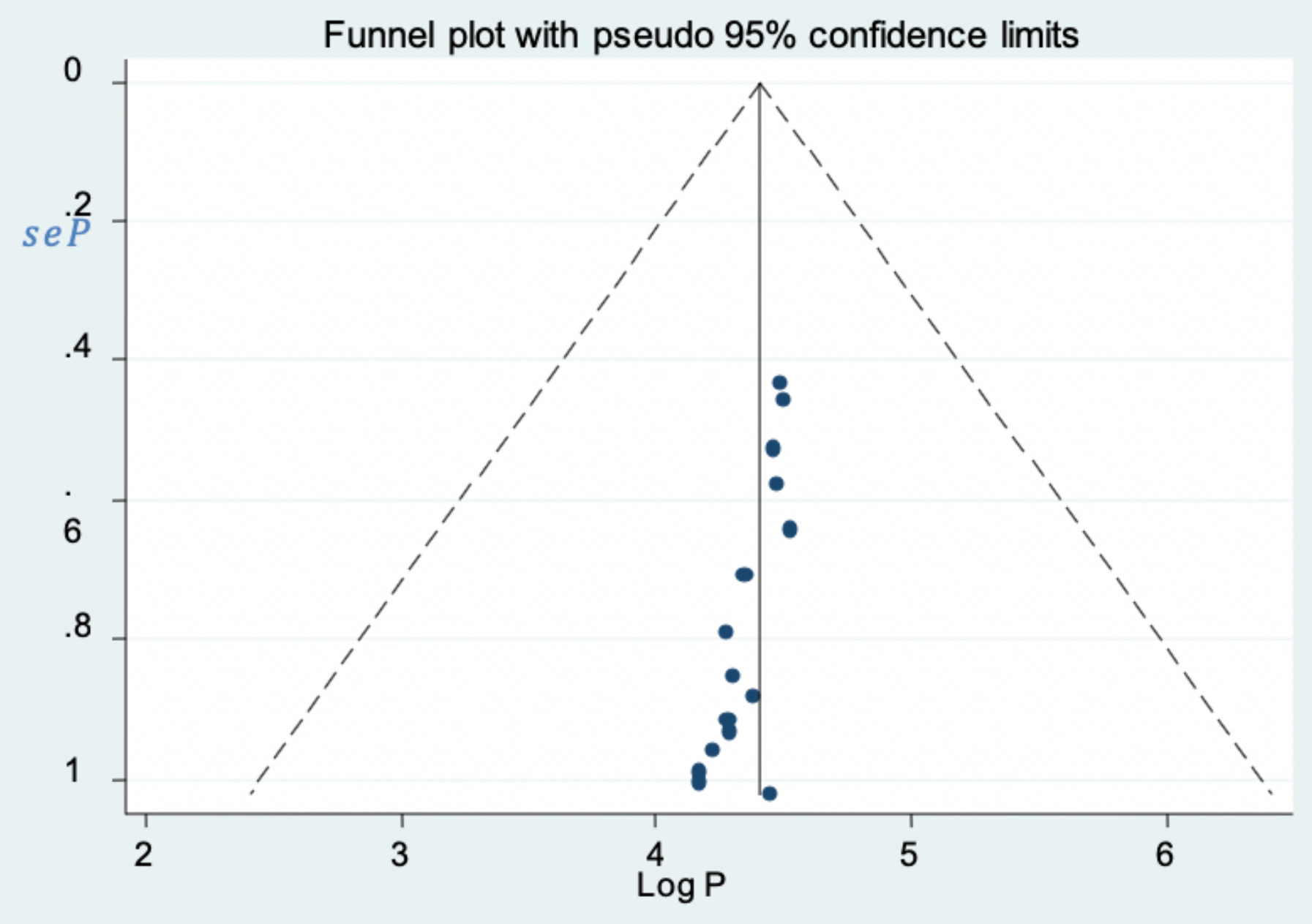

Figure 3

Funnel plot for the ART adherence 
Authol

ES $(95 \% \mathrm{Cl}) \quad$ Weight

Molla et al./2018

Shewaye et al.2016

Wendwesen et al./2017

Abadiga/2019

Overall $(\mathrm{I}$-squared $=51.8 \%, p=0.101$

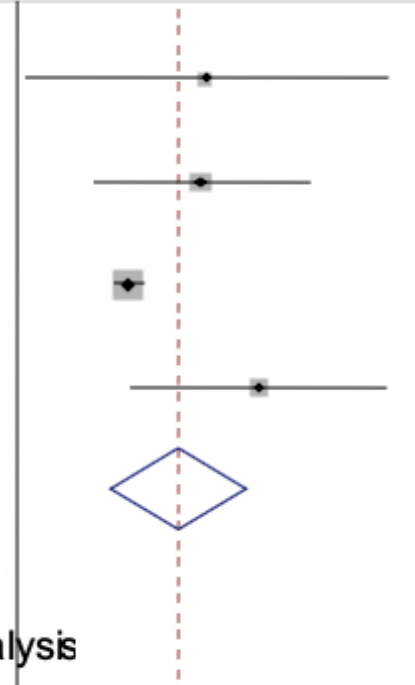

$3.65(1.06,12.59) 1.06$

$3.52(1.68,7.37) 22.15$

$2.15(1.94,2.39) 48.65$

$5.27(2.20,12.62) 8.15$

$2.99(1.88,4.77) 100.00$

NOTE: Weights are from random effects analysis

.11

20

Figure 4

The effect of HIV disclosure on HAART adherence

\section{Supplementary Files}

This is a list of supplementary files associated with this preprint. Click to download.

- PRISMA2009checklist.doc 